\title{
Shedding more light on the use of mechanical aortic valve replacement in patients with congenital heart disease
}

\author{
Paul J. Chai, MD
}

\author{
From the Columbia University Medical Center, New York, NY. \\ Disclosures: Author has nothing to disclose with regard to commercial support. \\ Received for publication Aug 20, 2018; accepted for publication Aug 24, 2018; available ahead of print Sept 25, \\ 2018. \\ Address for reprints: Paul J. Chai, MD, Columbia University Medical Center, 3959 Broadway, CHN 270, New \\ York, NY 10032 (E-mail: pjc2164@cumc.columbia.edu). \\ J Thorac Cardiovasc Surg 2019;157:341 \\ $0022-5223 / \$ 36.00$ \\ Copyright (C) 2018 Published by Elsevier Inc. on behalf of The American Association for Thoracic Surgery \\ https://doi.org/10.1016/j.jtcvs.2018.08.047
}

Myers and colleagues ${ }^{1}$ from Boston present their 14-year data on outcomes after mechanical aortic valve replacement in patients with congenital heart disease. In this study, they looked at 121 pediatric patients with mechanical aortic valve replacement and sought to identify the incidence of adverse outcomes such as death or thromboembolic events. Patients were mainly aged 12 to 22 years, and the median follow-up was 5 years. The authors found a survival of $90 \%$ at 1 year, $85 \%$ at 5 years, and $81 \%$ at 10 years. Freedom from reoperation was $90 \%$ at 7 years and $78 \%$ at 10 years.

This study has a heterogeneous group of patients (some single-ventricle and biventricular conversion cases were included), which is typical for patients who receive aortic valve replacement at pediatric and congenital centers. This leads to some limitations in the analysis of mortality and adverse outcomes because the underlying disease can play a confounding role from the procedure itself. As a result, the article is more of a general overall reflection of the outcomes of mechanical aortic valve replacement at a major pediatric cardiac center.

Aortic valve disease can be a challenging issue in the pediatric population, and studies such as this are valuable in identifying the issues that occur when mechanical prostheses are used. We are starting to realize that the "one and done" idea of mechanical prostheses no longer holds, and the idea that mechanical valve prostheses will last "forever" is certainly not the case. Pannus formation and thromboembolic issues remain a significant factor over the lifetime of a child or young adult. A recent study comparing long-term outcomes of the Ross procedure versus mechanical aortic valve replacement in adults

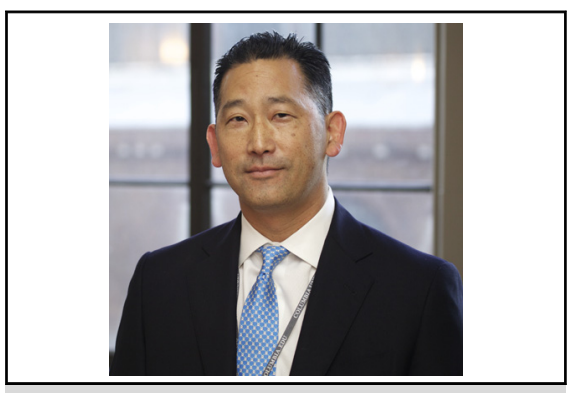

Paul J. Chai, MD

Central Message

Mechanical aortic valve replacement in patients with congenital heart disease is reported.

See Article page 329. surprisingly showed improved freedom from cardiac and valve-related mortality, as well as a significant reduction in stroke or bleeding events with the Ross procedure. ${ }^{2}$

In time, we will continue to gather more information on the long-term results with aortic valve replacement in our pediatric population. New options are starting to surface, including the procedure by Ozaki and colleagues ${ }^{3}$ or even modifications in the anticoagulation strategies for mechanical valves. ${ }^{4}$ Ultimately, these will all lead to further understanding and improvement in our treatment of aortic valve disease in children and young adults.

\section{References}

1. Myers PO, Mokashi SA, Horgan E, Borisuk M, Mayer JE Jr, del Nido P, et al. Outcomes after mechanical aortic valve replacement in children and young adults with congenital heart disease. J Thorac Cardiovasc Surg. 2019;157:329-40.

2. Mazine A, David TE, Rao V, Hickey EJ, Christie S, Manlhiot C, et al. Long-term outcomes of the Ross Procedure versus mechanical aortic valve replacement. Circulation. 2016;134:576-85.

3. Ozkai S, Kawase I, Yamashita J, Uchida S, Nozawa Y, Takatoh M, et al. A total of 404 cases of aortic valve reconstruction with glutaraldehyde-treated autologous pericardium. J Thorac Cardiovasc Surg. 2014;147:301-6.

4. Puskas J, Gerdisch M, Nichols D, Quinn R, Anderson C, Rhenman B, et al Reduced anticoagulation after mechanical aortic valve replacement: interim results from the prospective randomized on-X valve anticoagulation clinical trial. J Thorac Cardiovasc Surg. 2014;147:1202-10. 